\title{
O LUGAR E O TEMPO DAS CULTURAS INFANTIS NAS PESQUISAS BRASILEIRAS
}

Fabiana de Oliveira ${ }^{1}$

\section{INTRODUÇÃO}

A presente reflexão se configura como um dos resultados da pesquisa em andamento desenvolvida por meio do projeto de demanda universal com financiamento da Fapemig ${ }^{2}$ denominado "As contribuições teórico-metodológicas de Florestan Fernandes para as pesquisas com crianças no Brasil e as interfaces com a Sociologia da Infância”.

Um dos objetivos do projeto foi justamente compreender o lugar e os tempos nos quais os estudos envolvendo as culturas infantis foram realizados nas pesquisas brasileiras tendo como referencial teórico Florestan Fernandes, bem como, a Sociologia da Infância. Florestan Fernandes foi o sociólogo pioneiro a tratar da discussão da cultura infantil no Brasil e se constituiu como uma matriz inicial de referência que nos ajudou a compreender o modo de organização e as territorialidades do desenvolvimento de um estudo dessa natureza junto às crianças.

Compreende-se a infância como uma construção social vem sendo influenciada por vários campos como a Pedagogia, a Psicologia e a presença cada vez mais ampla a partir da década de 1990 da Sociologia da Infância. Em virtude da nossa reflexão sobre o lugar e o tempo das culturas infantis nas pesquisas, a área da Geografia da Infância será de grande importância para a discussão do conceito de território que envolve a articulação entre os espaços e a sua vivência na constituição de subjetividades por meio da cultura do grupo envolvido, pois

\footnotetext{
A infância se dá num amplo espaço de negociação que implica a produção de culturas de criança, do lugar, dos lugares destinados às crianças pelo mundo adulto e suas instituições e das territorialidades de criança, resultando desse embate uma configuração à qual chamamos de
}

\footnotetext{
1 Formada em Pedagogia pela Universidade Federal de São Carlos (UFSCar). Mestrado e Doutorado em Educação pela mesma instituição. Realizou estágio de doutoramento no Instituto da Criança na Universidade do Minho (UM/Portugal). Pós-Doutorado pela USP-RP. É docente do Programa de Pós-Graduação em Educação da Universidade Federal de Alfenas (UNIFAL-MG). fabiana.oliveiraunifal@gmail.com
}

2 Fundação de Amparo à Pesquisa de Minas Grais (FAPEMIG). 
territorialidades infantis, cujo campo de reflexão é a Geografia da Infância (LOPES, 2008, p. $68)$.

A produção no campo da infância vem ganhando um espaço de destaque e um crescente interesse, pois nos últimos dez ou vinte anos, a atenção da opinião pública em direção às crianças e aos jovens tem crescido consideravelmente, como exemplifica Sgritta (1997) com o interesse da comunidade científica. Os comitês e equipes de observação têm sido estabelecidos no nível nacional e internacional, os institutos oficiais de estatística têm finalmente recolhido dados sobre a condição da infância.

Esta concepção ganhou maior visibilidade a partir da ampliação do campo da Sociologia da Infância, mas podemos demarcar o início dessa discussão no Brasil a partir dos estudos de Florestan Fernandes na década de 1940, ou seja, um estudo pioneiro sobre o processo socialização pelas próprias crianças e a produção de suas culturas.

Assim, partimos do princípio que o processo de socialização não se dá somente por meio da reprodução por parte da criança do que lhe é transmitido pelos adultos, mas também das suas possibilidades de reinvenção/recriação desta cultura adulta, o que Corsaro (2011) denominou de reprodução interpretativa:

O termo interpretativo abrange os aspectos inovadores e criativos da participação infantil na sociedade. Na verdade (...), as crianças criam e participam de suas próprias e exclusivas culturas de pares quando selecionam ou se apropriam criativamente de informações do mundo adulto para lidar com suas próprias e exclusivas preocupações. O termo reprodução inclui a ideia de que as crianças não se limitam a internalizar a sociedade e a cultura, mas contribuem ativamente para a produção e mudança culturais (CORSARO, 2011, p.31-32).

Segundo o referido autor é em torno do conceito de reprodução que ocorreram as principais rupturas no campo da sociologia da infância. A partir disso, podemos compreender que as crianças também produzem culturas, as culturas de pares. O termo pares é utilizado por Corsaro (2011) para se "referir ao corte ou o grupo de crianças que passa seu tempo junto" (p.153). Assim, as culturas infantis ou cultura de pares referem-se às rotinas, atividades, valores e interesses que as crianças produzem e compartilham com os demais. 
A pesquisa de Florestan Fernandes realizada para a cadeira de Sociologia I do curso de Ciências Sociais da Faculdade de Filosofia, Ciências e Letras da Universidade de São Paulo no ano de 1941, teve inicialmente um recorte bastante amplo a respeito do folclore na cidade de São Paulo.

Somente depois de iniciar sua experiência com o trabalho de campo e de estar mais esclarecido sobre determinados aspectos dos dados encontrados, é que Florestan decidiu restringir-se à coleta de dados apenas relacionados ao folclore infantil. A partir dos dados coletados por Florestan Fernandes (1961), o mesmo pôde constatar a partir de outros trabalhos já realizados que a origem dos elementos do folclore infantil estava no folclore ibérico, ou seja, de raízes portuguesa e castelhana. Porém para Florestan, em sua pesquisa esta foi uma simples constatação, e que, para ele parecia insuficiente e eram necessárias novas indagações a respeito dessa temática, e isso o levou ao estudo do folclore infantil por meio dos grupos de crianças conhecidos como "trocinhas". As observações foram realizadas nos bairros de Bom Retiro, Lapa, Bela Vista, Brás e Pinheiros.

O campo aberto pelos Estudos da Infância e, especificamente pela Sociologia da Infância enquanto área de estudo e pesquisa, possibilitou a abertura para se pensar na possibilidade do brincar enquanto atividade simbólica de produção de cultura. Então, podemos considerar a existência de uma cultura da infância que nos aponta um novo entendimento da criança e da infância. Neste sentido, podemos incluir uma abertura no campo das ideias sociológicas que, até então, não tinham reservado às crianças uma atenção específica, pois sempre eram estudadas como um fenômeno interligado à escola e à família e atrelada à discussão sobre a socialização da criança como uma forma de inculcação dos valores da sociedade adulta.

A partir dos anos 80, os trabalhos sociológicos sobre a infância se multiplicaram. Várias publicações em revistas especializadas como era o caso da Sociological Studies of Children e outras que não eram especializadas em assuntos da infância, e ainda, as obras que começaram a aparecer, como foi caso das publicações de Corsaro, Cunningham, James, Prout, Jenks e Qvortrup entre outros.

De acordo com Montandon (2001) foi, sobretudo, nos Estados Unidos durante os anos 20 que o interesse pelos estudos da criança obteve um avanço. Foi por volta do final do século passado que em meio a um contexto de industrialização crescente e também de urbanização e imigração que emergiu um interesse pelos problemas da criança principalmente relacionados às questões do trabalho infantil, deficiência mental e delinquência juvenil. 
Nas publicações em língua francesa temos o exemplo de uma primeira tentativa de mudança de olhar sobre a infância que diz respeito ao número da Revue de I'Institute de Sociologie de Bruxelles publicada em 1994 cujo título foi "Infâncias e Ciências Sociais" (Sirota, 2001).

Os sociólogos da infância se reuniram pela primeira vez em 1990, no Congresso Mundial de Sociologia. A Sociologia da Infância é um dos mais recentes comitês de pesquisa da Associação Internacional de Sociologia (ISA) e também se constitui como um dos últimos grupos de trabalho criados na Associação Internacional de Sociólogos de Língua Francesa (AISLF).

Dentro da Associação de Sociólogos de Língua Francesa, dois Comitês se interessaram pela infância: de um lado, os sociólogos da família e de outro, os sociólogos da educação. Os primeiros organizaram um primeiro evento voltado para as questões da infância em 1995 visando tornar a criança um parceiro ou ator dentro da estrutura familiar. Os segundos buscaram mostrar a criança não somente como um "aluno", mas também enquanto um ator social dentro do âmbito dos estudos etnográficos a partir de uma socioantropologia da infância (Sirota, 2001).

Em Portugal de acordo com Sarmento (2005) este campo ainda está em constituição, mas já possuem trabalhos realizados nesta perspectiva (teses, projetos de pesquisa, números temáticos de revistas) e os primeiros cursos de pós-graduação nesta área. A constituição deste campo se efetiva por meio da compreensão de dois objetos sociológicos: a infância e a criança como ator social pleno. Os pesquisadores mais conhecidos desse campo em Portugal são Manuel Sarmento, Natália Fernandes e Manuela Ferreira e Catarina Tomás.

Assim, podemos afirmar que ainda é um campo recente, em constituição e consolidação, mas que vem nos apresentar questionamentos muito relevantes sobre o modo que até então as crianças eram consideradas no campo da Psicologia, da Medicina, da Pedagogia e até da própria Sociologia (Sarmento, 2005 e 2006, Prout, 2005).

É a partir dessa fonte inicial que nos propusemos a refletir sobre o lugar e os tempos nos quais os estudos envolvendo as culturas infantis foram realizados nas pesquisas brasileiras. Partindo do princípio de que a infância é uma construção social, buscamos saber como a produção da infância e suas culturas infantis têm sido estudadas nas pesquisas considerando que o lugar e o tempo no qual as crianças vivem leva à produção de determinadas infâncias.

Nesse sentido, nos colocamos algumas questões norteadoras: onde os pesquisadores brasileiros têm buscado estudar as crianças e suas culturas infantis? É no espaço público das ruas, das 
praças? Ou é nos espaços fechados, institucionalizados das instituições educativas? Em qual tempo esses estudos foram realizados?

\section{ASPECTOS METODOLÓGICOS DA PESQUISA}

A pesquisa foi realizada por meio de levantamento bibliográfico realizado a partir das dissertações e teses da Biblioteca Digital de Teses e Dissertações (IBICT) no período de 1990 a 2015. O levantamento bibliográfico foi realizado inicialmente pela análise dos títulos visando identificar aqueles que estavam dentro da temática de pesquisa, bem como pela utilização dos seguintes descritores: Florestan Fernandes e cultura infantil (e suas derivações: cultura da infância, culturas infantis e cultura de pares). Esses descritores foram selecionados, pois o tema "cultura infantil" é um conceito fundante na obra de Florestan Fernandes, bem como para o campo da Sociologia da Infância. Encontramos um total de 40 pesquisas que foram as seguintes:

\begin{tabular}{|c|c|c|c|c|c|}
\hline TÍTULO & $\begin{array}{l}\text { PESQUISADOR } \\
\text { (A) }\end{array}$ & IES & TIPO & PROGRAMA & ANO \\
\hline $\begin{array}{l}\text { Jogo, Brincadeira } \\
\text { e Cultura na } \\
\text { educação infantil }\end{array}$ & Monica Fantin & UFSC & Dissertação & Educação & 1996 \\
\hline $\begin{array}{l}\text { Gestos nos cantos } \\
\text { da Lagoa Azul: } \\
\text { crianças } \\
\text { brincantes } \\
\text { produtoras } \\
\text { cultura }\end{array}$ & $\begin{array}{l}\text { Raulito Ramos } \\
\text { Guerra Filho }\end{array}$ & UNICAMP & Dissertação & Educação Física & 1998 \\
\hline $\begin{array}{l}\text { Educação } \\
\text { Cultura infantil } \\
\text { em creche: um } \\
\text { estudo sobre as } \\
\text { brincadeiras de } \\
\text { crianças } \\
\text { pequenininhas em } \\
\text { uma CEMEI de } \\
\text { Campinas }\end{array}$ & $\begin{array}{l}\text { Patrícia Dias } \\
\text { Prado }\end{array}$ & UNICAMP & Dissertação & Educação & 1998 \\
\hline $\begin{array}{l}\text { Desenhos de } \\
\text { outrora, desenhos } \\
\text { de agora: os } \\
\text { desenhos r de } \\
\text { crianças pequenas } \\
\text { do acervo de } \\
\text { Mário de Andrade }\end{array}$ & $\begin{array}{l}\text { Márcia } \\
\text { Aparecida } \\
\text { Gobbi }\end{array}$ & UNICAMP & Tese & Educação & 2004 \\
\hline
\end{tabular}




\begin{tabular}{|c|c|c|c|c|c|}
\hline $\begin{array}{l}\text { Imaginário } \\
\text { infantil e desenho } \\
\text { animado } \\
\text { cenário no } \\
\text { mundialização das } \\
\text { culturas }\end{array}$ & $\begin{array}{l}\text { Juliane Di Paulo } \\
\text { Queiroz } \\
\text { Odinnino }\end{array}$ & UNICAMP & Dissertação & Sociologia & 2004 \\
\hline $\begin{array}{l}\text { Traços da cultura } \\
\text { infantil: um estudo } \\
\text { com grupos de } \\
\text { crianças que } \\
\text { brincam } \\
\text { livremente }\end{array}$ & $\begin{array}{l}\text { Camila Tenório } \\
\text { Cunha }\end{array}$ & UNICAMP & Dissertação & Educação & 2005 \\
\hline $\begin{array}{l}\text { Praça Jerimum: } \\
\text { cultura infantil no } \\
\text { espaço público }\end{array}$ & Samy Lansky & UFMG & Dissertação & Educação & 2006 \\
\hline $\begin{array}{l}\text { Cultura infantil e } \\
\text { envelhecimento: o } \\
\text { que as crianças } \\
\text { têm a dizer sobre a } \\
\text { velhice?: um } \\
\text { estudo com } \\
\text { meninos e meninas } \\
\text { da perifiria de } \\
\text { Porto Alegre }\end{array}$ & $\begin{array}{l}\text { Anne Carolina } \\
\text { Ramos }\end{array}$ & UFRGS & Dissertação & Educação & 2006 \\
\hline \begin{tabular}{lr} 
Círculos & de \\
cultura infantil: & o \\
método & Paulo \\
Freire & na \\
alfabetização & de \\
crianças: & um \\
estudo & \\
aproximativo & \\
\multicolumn{2}{l}{ socioconstrutivista }
\end{tabular} & $\begin{array}{l}\text { Cristhiane de } \\
\text { Souza }\end{array}$ & UNINOVE & Dissertação & Educação & 2006 \\
\hline $\begin{array}{l}\text { O desenho infantil } \\
\text { em seu cotidiano: } \\
\text { imagem, cultura } \\
\text { lúdica } \\
\text { socialização }\end{array}$ & Alessandra Klug & UDESC & Dissertação & Artes Visuais & 2007 \\
\hline $\begin{array}{l}\text { Imagens } \\
\text { Infância: } \\
\text { brincadeira, } \\
\text { brinquedo } \\
\text { cultura }\end{array}$ & $\begin{array}{l}\text { Levindo Diniz } \\
\text { Carvalho }\end{array}$ & UFMG & Dissertação & Educação & 2007 \\
\hline
\end{tabular}




\begin{tabular}{|c|c|c|c|c|c|}
\hline $\begin{array}{lr}\text { As crianças e } & \text { o } \\
\text { exercício } & \text { das } \\
\text { práticas } & \text { de } \\
\text { autoridade } & \end{array}$ & $\begin{array}{l}\text { Flávia Miller } \\
\text { Naethe Motta }\end{array}$ & PUC Rio & Dissertação & Educação & 2007 \\
\hline $\begin{array}{l}\text { O quebra-cabeça } \\
\text { da cultura lúdica: } \\
\text { lugares, parcerias } \\
\text { e brincadeiras das } \\
\text { crianças: desafios } \\
\text { para políticas da } \\
\text { infância }\end{array}$ & $\begin{array}{l}\text { Rogério Costa } \\
\text { Würdig }\end{array}$ & UNISINOS & Tese & Educação & 2008 \\
\hline $\begin{array}{l}\text { Barulhar: a escuta } \\
\text { sensível da música } \\
\text { nas culturas da } \\
\text { infância }\end{array}$ & $\begin{array}{l}\text { Dulcimara } \\
\text { Lemos Lino }\end{array}$ & UFGRS & Tese & Educação & 2008 \\
\hline $\begin{array}{l}\text { Eu gosto de } \\
\text { brincar com os do } \\
\text { meu tamanho!: } \\
\text { culturas infantis e } \\
\text { cultura escolar - } \\
\text { entrelaçamentos } \\
\text { para o } \\
\text { pertencimento } \\
\text { etário na } \\
\text { instituição escolar }\end{array}$ & $\begin{array}{l}\text { Cinthia Votto } \\
\text { Fernandes }\end{array}$ & UFRGS & Dissertação & Educação & 2008 \\
\hline $\begin{array}{l}\text { Da educação } \\
\text { infantil ao ensino } \\
\text { fundamental: com } \\
\text { a palavra a } \\
\text { criança: } \\
\text { sobre } \\
\text { perspectiva } \\
\text { infantil } \\
\text { do no } \\
\text { escolar }\end{array}$ & $\begin{array}{l}\text { Teresa Cristina } \\
\text { Fernandes } \\
\text { Teixeira }\end{array}$ & USP & Dissertação & Educação & 2008 \\
\hline $\begin{array}{l}\text { As culturas } \\
\text { infantis no espaço } \\
\text { e tempo do recreio: } \\
\text { constituindo } \\
\text { singularidades } \\
\text { sobre a criança }\end{array}$ & $\begin{array}{l}\text { Ana Paula } \\
\text { Vieira e Souza }\end{array}$ & UFPA & Dissertação & Educação & 2009 \\
\hline $\begin{array}{lr}\text { A construção de } \\
\text { significados } \\
\text { brincadeiras } \\
\text { faz-de-conta } \\
\text { crianças de } \\
\text { turma de educação } \\
\text { infantil ribeirinha } \\
\text { da Amazônia }\end{array}$ & $\begin{array}{lr}\text { Sonia } & \text { Regina } \\
\text { dos } & \text { Santos } \\
\text { Teixeira } & \end{array}$ & UFPA & Tese & Psicologia & 2009 \\
\hline
\end{tabular}




\begin{tabular}{|c|c|c|c|c|c|}
\hline $\begin{array}{l}\text { Culturas infantis: } \\
\text { crianças } \\
\text { brincando na rua e } \\
\text { em uma pré-escola } \\
\text { na cidade da Praia } \\
\text { (Cabo Verde) }\end{array}$ & $\begin{array}{l}\text { Dijanira Noemy } \\
\text { Vieira Lopes dos } \\
\text { Santos }\end{array}$ & UNICAMP & Dissertação & Educação & 2010 \\
\hline $\begin{array}{l}\text { A infância pelo } \\
\text { olhar das crianças } \\
\text { do MST: ser } \\
\text { criança, culturas } \\
\text { infantis e educação }\end{array}$ & $\begin{array}{l}\text { Elisangela } \\
\text { Marques Moraes }\end{array}$ & UFPA & Dissertação & Educação & 2010 \\
\hline $\begin{array}{l}\text { Conflito na } \\
\text { educação infantil: } \\
\text { o que as crianças } \\
\text { têm a dizer sobre } \\
\text { ele? }\end{array}$ & $\begin{array}{l}\text { Bianca } \\
\text { Rodriguez Corsi }\end{array}$ & USP & Dissertação & Educação & 2010 \\
\hline $\begin{array}{l}\text { Música na escola: } \\
\text { um desafio à luz da } \\
\text { cultura da infância }\end{array}$ & $\begin{array}{l}\text { Silvia Salles } \\
\text { Leite Lombardi }\end{array}$ & UNESP & Dissertação & Música & 2010 \\
\hline $\begin{array}{l}\text { O brinquedo na } \\
\text { educação infantil } \\
\text { como promotor } \\
\text { das culturas da } \\
\text { infância } \\
\text { humanização }\end{array}$ & $\begin{array}{l}\text { Larissa } \\
\text { Aparecida } \\
\text { Trindade dos } \\
\text { Santos }\end{array}$ & UNESP & Dissertação & Educação & 2010 \\
\hline $\begin{array}{l}\text { Compreensão de } \\
\text { professoras de } \\
\text { educação infantil } \\
\text { acerca das } \\
\text { brincadeiras de } \\
\text { faz-de-conta e das } \\
\text { culturas infantis }\end{array}$ & $\begin{array}{l}\text { Graciele de } \\
\text { Souza Colling }\end{array}$ & FURB & Dissertação & Educação & 2010 \\
\hline $\begin{array}{lr}\text { A } & \text { educação } \\
\text { infantil no olho do } \\
\text { furacão: } \\
\text { movimento } \\
\text { político e } \\
\text { contribuições } & \text { as } \\
\text { Sociologia } & \text { da } \\
\text { Infância } & \end{array}$ & $\begin{array}{l}\text { Fabiana Oliveira } \\
\text { Canavieira }\end{array}$ & UNICAMP & Dissertação & Educação & 2010 \\
\hline $\begin{array}{l}\text { Infância } r \text { e } \\
\text { literatura infantil: } \\
\text { o que pensam, } \\
\text { dizem e fazem as } \\
\text { crianças a partir } \\
\text { da leitura de } \\
\text { histórias? } \\
\text { produção } \\
\text { culturas infantis }\end{array}$ & $\begin{array}{ll}\text { Debora } & \text { Perillo } \\
\text { Samori } & \end{array}$ & USP & Dissertação & Educação & 2011 \\
\hline
\end{tabular}




\begin{tabular}{|c|c|c|c|c|c|}
\hline $\begin{array}{l}\text { no } 1^{\circ} \text { ano do } \\
\text { Ensino } \\
\text { Fundamental. }\end{array}$ & & & & & \\
\hline $\begin{array}{l}\text { Desenho: } \text { diálogos } \\
\text { étnicos e culturais } \\
\text { com } \\
\text { Guarani }\end{array}$ & $\begin{array}{l}\text { Renata Lúcia de } \\
\text { Assis Gama }\end{array}$ & UFES & Dissertação & Educação & 2011 \\
\hline $\begin{array}{l}\text { Os olhares das } \\
\text { crianças sobre a } \\
\text { cidade } \\
\text { Vitória/ES: } \quad \text { de } \\
\text { escola como um } \\
\text { ponto de partida }\end{array}$ & $\begin{array}{l}\text { Ana Moscon de } \\
\text { Assis Pimentel } \\
\text { Teixeira }\end{array}$ & UFES & Dissertação & Educação & 2012 \\
\hline $\begin{array}{lr}\text { O diálogo } & \text { entre } \\
\text { aspectos } & \text { da } \\
\text { cultura } & \text { científica } \\
\text { com as } & \text { culturas } \\
\text { infantis } & \text { na } \\
\text { educação infantil }\end{array}$ & $\begin{array}{l}\text { Sandra } \\
\text { Fagionato } \\
\text { Ruffino }\end{array}$ & UFSCAR & Tese & Educação & 2012 \\
\hline $\begin{array}{l}\text { Linguagem dos } \\
\text { quadrinhos e } \\
\text { culturas infantis: é } \\
\text { uma história } \\
\text { escorridinha }\end{array}$ & $\begin{array}{l}\text { Marta Regina } \\
\text { Paulo da Silva }\end{array}$ & UNIR & Tese & Educação & 2012 \\
\hline $\begin{array}{l}\text { A reprodução } \\
\text { interpretativa do } \\
\text { obsceno infantil na } \\
\text { cultura de pares }\end{array}$ & $\begin{array}{l}\text { Cibele Noronha } \\
\text { de Carvalho }\end{array}$ & UFMG & Dissertação & Educação & 2013 \\
\hline $\begin{array}{l}\text { Culturas Infantis: } \\
\text { crianças plurais, } \\
\text { plural da infância } \\
\text { no cotidiano da } \\
\text { educação infantil }\end{array}$ & $\begin{array}{l}\text { Gleisy } \quad \text { Vieira } \\
\text { Campos }\end{array}$ & UFU & Dissertação & Educação & 2013 \\
\hline $\begin{array}{lr}\text { O brincar } & \text { nas } \\
\text { produções } & \text { do } \\
\text { conhecimento } & \text { da } \\
\text { creche UFF } & \end{array}$ & $\begin{array}{l}\text { Cássia Cristina } \\
\text { Barreto Santos }\end{array}$ & UERJ & Dissertação & Educação & 2013 \\
\hline $\begin{array}{l}\text { "Vem, agora eu te } \\
\text { espero" } \\
\text { Institucionalização } \\
\text { e Qualidade das } \\
\text { interações na } \\
\text { creche: um estudo } \\
\text { comparativo }\end{array}$ & $\begin{array}{l}\text { Silvia Neli } \\
\text { Falcão Barbosa }\end{array}$ & PUC Rio & Tese & Educação & 2013 \\
\hline
\end{tabular}




\begin{tabular}{|c|c|c|c|c|c|}
\hline $\begin{array}{l}\text { Reprodução } \\
\text { interpretativa na } \\
\text { infância tapeba: } \\
\text { um estudo sobre a } \\
\text { apropriação } \\
\text { cultural dessa } \\
\text { etnia }\end{array}$ & $\begin{array}{l}\text { Maria de Fátima } \\
\text { Brito Fontenele } \\
\text { Oliveira }\end{array}$ & UFC & Dissertação & Educação & 2014 \\
\hline $\begin{array}{l}\text { O meu cabelo é } \\
\text { assim ... igualzinho } \\
\text { o da bruxa, todo } \\
\text { armado: } \\
\text { hierarquização e } \\
\text { racialização das } \\
\text { crianças } \\
\text { pequenininhas } \\
\text { negras na } \\
\text { educação infantil }\end{array}$ & Flávio Santiago & UNICAMP & Dissertação & Educação & 2014 \\
\hline $\begin{array}{l}\text { A infância resiste à } \\
\text { pré-escola? }\end{array}$ & $\begin{array}{l}\text { Lenilda } \\
\text { Cordeiro de } \\
\text { Macedo }\end{array}$ & UFPB & Tese & Educação & 2014 \\
\hline 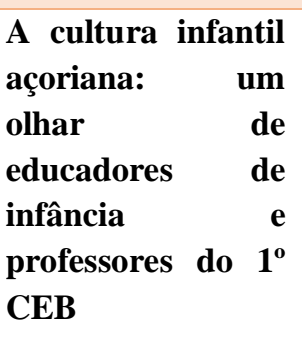 & $\begin{array}{l}\text { Diana Sofia } \\
\text { Silva Félix }\end{array}$ & UNIR & Dissertação & Educação & 2015 \\
\hline $\begin{array}{l}\text { Educação infantil } \\
\text { popular: } \\
\text { possibilidades a } \\
\text { partir da ciranda } \\
\text { infantil do MST }\end{array}$ & $\begin{array}{l}\text { Fábio Accardo } \\
\text { de Freitas }\end{array}$ & UNICAMP & Dissertação & Educação & 2015 \\
\hline $\begin{array}{l}\text { Manifestações de } \\
\text { conteúdos } \\
\text { televisivos nas } \\
\text { culturas infantis e } \\
\text { interpretações das } \\
\text { professoras no } \\
\text { contexto pré- } \\
\text { escolar }\end{array}$ & $\begin{array}{l}\text { Jéssika Naiara } \\
\text { da Silva }\end{array}$ & UNESP & Dissertação & Educação & 2015 \\
\hline
\end{tabular}

Organizamos o material por meio de leituras e fichamentos. Esses fichamentos contêm os apontamentos das categorias que foram sendo encontradas nos documentos e foram as seguintes: jogos, mídias, desenhos, pesquisa com criança, educação infantil e diversidade. De acordo com Gomes (1994, p.70) "as categorias podem ser definidas antes do trabalho de campo, na fase exploratória da pesquisa, ou a partir da coleta de dados". 
As categorias de análise foram estabelecidas a partir de um princípio único de classificação por meio dos assuntos recorrentes nos documentos, sendo que no conjunto de categorias todos os princípios e artigos foram incluídos, mas considerando que nenhum artigo ou princípio fosse colocado em mais de uma categoria.

\section{DISCUSSÃO DOS DADOS}

Os dados encontrados apontam que o primeiro estudo registrado nesse banco de dados envolvendo os descritores utilizados na pesquisa se refere ao ano de 1996. Dois anos depois temos o registro de duas pesquisas. Após cinco anos, entre os anos de 2004 a 2010 tivemos outras pesquisas também com interesse nessa temática contabilizando um total de 24 pesquisas num período de seis anos. E nos anos que se seguiram até 2015 tivemos mais 15 pesquisas num período de cinco anos configurando um crescimento oscilante que não superou o resultado encontrado no período anterior.

Um dado relevante a se considerar é que as pesquisas se concentraram em sua grande maioria a partir dos anos 2000. Uma das hipóteses que podemos levantar acerca desse dado se refere ao fato de um maior conhecimento pelos pesquisadores acerca das culturas infantis e da sociologia da infância no Brasil, pois na Europa esse movimento foi sentido desde a década de 1990, mas aqui esse "boom” só foi sentido a partir dos anos 2000, sendo uma área ainda em construção e consolidação. Esse dado nos leva a considerar a hipótese da influência pouco visível das contribuições de Florestan Fernandes acerca da cultura infantil e esse campo de estudos no Brasil.

Os resultados encontrados nos permitem afirmar que em sessenta e três por cento das pesquisas analisadas, os estudos desenvolvidos sobre a cultura infantil foram realizados no espaço da educação infantil ou nos anos iniciais do ensino fundamental, ou seja, estamos estudando as culturas infantis considerando como centralidade a territorialidade e o tempo escolar/institucionalizado.

Assim, o conceito de topofilia de Tuan se mostra extremamente importante para essa reflexão, pois pode ser compreendido como "o elo afetivo entre a pessoa e o lugar ou ambiente físico" (TUAN, 1980, p. 05 apud LOPES, 2013, p. 287). Associado a essa reflexão temos o conceito de território, já que não podemos deixar de considerar que "o território é fundamentalmente um espaço definido e limitado por e a partir de relações de poder" (SOUZA, 1995, p. 78 apud LOPES, 2013, p. 290).

A partir dessas relações de poder que marcam as relações entre adultos e crianças, ou seja, o modo como as crianças são ensinadas e inseridas num determinado espaço, e nesse caso específico, estamos tratando do espaço institucional da educação infantil, há produção de representações que 
fazem emergir imagens e discursos sobre a infância, essa infância que é também é produzida por esse aparato escolar.

É nesse sentido que Corsaro (2011) afirma que a cultura de pares ou culturas infantis é afetada pelos adultos, sobretudo pela rotina adulto-criança presente nas famílias e nas instituições de educação infantil como um dos primeiros espaços externos de socialização das crianças. Nesse sentido, de acordo com o autor, "as crianças ativamente ingressam e tornam-se participantes e colaboradores de cultura de pares locais pela primeira vez quando se movem para fora do âmbito familiar em direção à comunidade adjacente" (CORSARO, 2011, p.154).

Sarmento (2005) também compartilha da compreensão de que as culturas infantis não são exclusivas do universo infantil, mas também de todas as influências do mundo que as rodeia (os modos de vida dos adultos, os processos de institucionalização, a influência da mídia, do consumo e da indústria cultural, e também a utilização de computadores e da internet) envolvendo, portanto, um movimento de reprodução e interpretação do mundo adulto.

As pesquisas analisadas em sua maioria apresentam que as crianças não são consideradas também como produtoras do espaço das instituições educativas, mas inseridos nesse lugar de forma homogeneizante e universal como se a vivência desse espaço devesse ser igualmente vivida por todas as crianças, já que

Essa leitura, calcada em um suposto caminho que todas as crianças deveriam percorrer na sistematização da construção de sua inserção espacial, de forma universal, as manteve deslocadas de seus contextos culturais e de seus pares, e também afastadas dos momentos de organização e produção dos espaços em que vivem e, historicamente, negligenciaram suas linguagens espaciais (LOPES, 2008, p. 76).

Associado a esse espaço institucional temos também o uso do tempo que de acordo com Barbosa (2006, p. 141), "os tempos de grande parte das instituições educacionais continuam, em sua maioria, sendo o tempo do início da modernidade, o tempo rígido, mecânico, absoluto". Ainda segundo essa autora, esse tempo institucional se organiza ao que ela denomina de "tempo do capital" que passa a organizar a vida das crianças dentro das instituições de educação infantil, sendo que esse horário das atividades pertence ao controle do adulto e raramente é decidido pelas crianças.

Porém, o que as pesquisas apontam é que as crianças apresentavam clareza deste controle e programação, pois sempre procuravam meios para driblarem esse controle dos adultos em suas atividades a partir do que Corsaro (2011) denomina de ajustes secundários que possibilitam às 
crianças uma certa possibilidade de controle sobre suas ações, pois compreendem que as regras existem, porém, também podem ser alteradas e, por isso, desafiam a autoridade dos adultos.

Nesse sentido, as crianças não vivenciam essas rotas traçadas a elas de forma passiva, mas vão buscando formas de subverter esse controle adulto do tempo e do espaço institucional que lhe é reservado, pois "para as crianças a prática espacial é uma prática de lugar-território, posto que apreendem o espaço em suas escalas vivenciais, a partir de seus pares, do mundo adulto, da sociedade em que estão inseridas" (LOPES, 2008, p. 78).

A pesquisa pioneira desenvolvida por Florestan teve como lócus o espaço da cidade de São Paulo, especificamente os bairros de Bom Retiro, Lapa, Bela Vista, Brás e Pinheiros, porém optou pela análise mais minuciosa das "trocinhas" do Bom Retiro. A observação foi o principal instrumento de coleta dos dados seguida de uma descrição minuciosa e "fiel" que segundo Florestan Fernandes (1961) permitiu “não só a obtenção dos vários elementos do cancioneiro literário, no caso as diversas composições do folclore infantil, como facilitou, extraordinariamente, o estudo da vida social dos imaturos nos grupos infantis" (p. 201).

Florestan se debruçou no estudo específico das "trocinhas" formadas nas ruas pelas crianças com faixa etária a partir dos sete anos que, segundo o sociólogo apresentavam uma consciência grupal e isso fazia da "trocinha" um grupo social constituído pelos seguintes elementos: interação, associação e sociabilidade. Ou seja, esses elementos compõem uma ordem social que de acordo com Fernandes (1970) "se constitui como um sistema de referências de caráter universal (...) onde os organismos se agregam ou se associam socialmente, existindo certas regularidades no modo de coexistência ou de convivência deles entre si” (p. 25).

Um dado presente nas pesquisas que analisaram as brincadeiras nas ruas se refere à diferença do nível de liberdade entre as crianças. Em sua maioria, as meninas não tinham a mesma liberdade que os meninos para brincarem na rua, muitas delas só tinham permissão para brincar no quintal ou em frente de casa. Dado esse também presente nos estudos de Florestan, mas é preciso pontuar que mesmo em proporção menor nas pesquisas, as meninas aparecem brincando em espaços públicos como as praças e se verifica uma semelhança nas brincadeiras recortadas pela questão de gênero como o brincar de casinha.

Florestan Fernandes (1961) também encontrou a questão de gênero aliada ao fator etário como uma forma de diferenciação entre os grupos formados por meninas e por meninos. As brincadeiras das meninas segundo o sociólogo eram menos violentas e agrupavam-se segundo o que se 
convencionou designar de "atribuições femininas" como brincar de "casinha", "de mamãe e filhinha", de "comidinha", ou seja, eram brinquedos mais sedentários, o que também as diferenciava dos meninos.

As "trocinhas" das meninas também não recebiam nomes, e o papel da líder era menos preponderante que entre os meninos, pois nesse caso, o papel é mais de animador do que de dirigente. As meninas geralmente agrupavam-se nas calçadas ou nos quintais de suas casas e seus agrupamentos eram denominados em alguns bairros de "trempe" ou "trempinha" (FERNANDES, 1961).

A questão etária também é um fator recorrente nas pesquisas analisadas envolvendo a organização dos grupos infantis que, em alguns momentos, os maiores e os menores brincam juntos, mas a organização desses grupos geralmente não ocorre por meio de uma formação mista de idades. Em relação à classe social, algumas das pesquisas analisadas apenas ilustraram as diferenças entre as crianças ao contextualizar os bairros onde elas moravam e o modo como pertencer a uma classe social influencia o tempo das crianças para o brincar, bem como, o local que essa brincadeira ocorria, sendo nas praças/ruas ou em condomínios fechados.

\section{CONSIDERAÇÕES FINAIS}

Os resultados encontrados por meio da análise das pesquisas nos permitem afirmar que os espaços destinados ao brincar são geralmente estudados a partir do espaço institucionalizado da educação infantil ou dos anos iniciais do ensino fundamental.

A escola acaba por se constituir a territorialidade infantil por excelência confirmando a invisibilidade das crianças em outros espaços públicos. As pesquisas analisadas quando buscam compreender a cultura infantil o fazem por meio do estudo do brincar que, com certeza, é uma categoria sociológica de extrema importância para se compreender a infância nas suas multiplicidades, mas é preciso também pensar as culturas infantis em sua manifestação em outros meios como, por exemplo, a presença e participação das crianças nos espaços públicos a partir das interações vivenciadas pelas crianças nas cidades. As pesquisas realizadas em praças e ruas apontaram que as crianças buscam formas de apropriação desses espaços historicamente constituídos pelo e para os adultos.

Sabemos que as crianças vivem um distanciamento dos espaços públicos, o que Sarmento (2007) denomina de "invisibilidade cívica". Essa invisibilidade é ocasionada principalmente pela institucionalização das crianças que, na verdade se constitui enquanto um movimento de controle dos 
corpos infantis. Isso gera de acordo com Sarmento (et al) "um confinamento da infância a um espaço social condicionado e controlado pelos adultos tendo como consequência o entendimento generalizado de que as crianças estão "naturalmente" privadas do exercício de direitos políticos" (2007, p. 184).

Lopes (2008) agrega mais uma negatividade que contribui para essa invisibilidade: "a do espaço e do tempo, a noção de uma infância percebida como sujeitos "a-topos", ou seja, de lugar nenhum, como sujeitos a-temporais, de tempo nenhum” (p. 74).

Esse confinamento da infância fica respaldado, ou melhor, justificado pela necessidade de proteção e cuidado que a moderna ideia de infância trouxe atrelada consigo e, produzindo a partir disso, uma criança dependente, frágil, imatura. Não estamos desconsiderando a atual organização das cidades que, acaba sendo um espaço que impede as crianças de circularem pelos seus espaços principalmente quando consideramos questões relacionadas ao trânsito e à violência. Nesse sentido, segundo Müller e Nunes (2014),

a hostilidade latente do espaço urbano, faz com que as crianças ainda tenham seus mecanismos de usos da cidade restringidos. Evidente que se trata aqui do espaço público, onde é raro encontrar crianças desacompanhadas de adultos. Esta faceta da cidade é lida como reticente à presença de crianças sem o acompanhamento do adulto responsável, situação reforçada pela mídia que privilegia matérias focando os perigos da cidade, que ameaçam a integridade física de seus habitantes. Uma concepção de criança como ser desprovido de autonomia termina sendo reforçada por esta representação midiática do espaço urbano (p. 665-666).

Apesar desse discurso da normalização estar calcado num poder sobre a vida, não podemos deixar de considerar que a vida também produz mecanismos de resistências a este poder, um poder da vida que faz fugir estes modelos de comportamento, de estética, de ser que são inculcados/transmitidos pela normalização. No entanto, desde o momento em que nascem as crianças estão inseridas em instituições que se baseiam neste poder normalizador, justamente por estas se enquadrarem no que Foucault denominou de instituições de sequestro (escola, fábrica, quartel, hospital, etc).

A educação compulsória da criança desde o momento do seu nascimento se configura como um aumento do nível do controle institucional sobre a criança. Este enquadramento da criança 
baseado nesta ideia de proteção visa também a sua exclusão do mundo do trabalho, das ruas e de outros espaços para sua recolocação em espaços mais "protegidos".

Apesar desse contexto no qual a criança está inserida, não podemos deixar de considerar que na perspectiva adotada nesse trabalho, a criança está sendo entendida como um ator social que também participa ativamente da reprodução e produção da sociedade, ou seja, um sujeito com agência e que, por isso,

Há momentos em que as crianças subvertem, há momentos em que interpretam, reproduzem o espaço e seus objetos, e há momentos de criação, de invenção, transformando-os, reorganizando os princípios da forma, função, localização, organização, representação e outros, a partir de suas ações (LOPES, 2008, p. 78).

A pesquisa desenvolvida aponta a necessidade de ampliação do campo da pesquisa envolvendo as crianças e suas culturas infantis para além do espaço escolar/institucionalizado visando a emergência de outros paradigmas, outras perspectivas na constituição de novas formas de compreender a constituição das diversas infâncias nos diversos lugares nos quais as crianças estão inseridas e tendo suas subjetividades produzidas.

Tínhamos até o ano de 2010 um contingente de 29 milhões de crianças na faixa etária entre zero e onze anos de idade vivendo em espaços urbanos, nesse sentido, segundo Müller e Nunes (2014, p. 660) "este dado nos motiva a pensar sobre as infinitas possibilidades de pesquisa sobre os mundos sociais das crianças em cidades". As autoras defendem a especificidade na consideração da área envolvendo a temática da infância e da cidade e, inclusive o desenvolvimento de uma linha de pesquisa em processo de consolidação.

\section{REFERENCIAS:}

BARBOSA, Maria Carmen S. Por amor e por força: rotinas na educação infantil. Porto Alegre: Artmed, 2006. CORSARO, Willian. Sociologia da Infância. Porto Alegre: Artmed, 2011.

Entrada no campo, aceitação e natureza da participação nos estudos etnográficos com crianças pequenas. In: Revista Educação \& Sociedade. N. 91. Vol. 26. Mai/ago. 2005. p.443-464.

FLORESTAN Fernandes. Folclore e Mudança social na cidade de São Paulo. São Paulo: Martins Fontes, 2004. Publicação da $1^{\text {a }}$ edição em 1961.

Elementos de Sociologia Teórica. São Pualo: Editora Nacional e Editora USP. 1970.

GOMES, Romeu. Análise dos dados em Pesquisa Qualitativa. In: Minayo, Cecília de Souza (org). Pesquisa Social: teoria, método e criatividade. Petrópolis (RJ): Vozes. 23 a ed. 1994.

JAMES, Allison \& JAMES, Adrian L. Constructing Childhood: theory, policy and social practice. New York: Palgrave Macmillan. 2004. 
LOPES, Jader J. M. Geografia das Crianças, Geografia das Infâncias: as contribuições da Geografia para os estudos das crianças e suas infâncias. Revista Contexto \& Educação. Ano 23. n. 79. jan/jun. 2008.p. 65-82.

Geografia da Infância: contribuições aos estudos das crianças e suas infâncias. Revista Educação Pública Cuiabá, v. 22, n. 49/1. maio/ago. 2013. P. 283-294.

MOLLO-BOUVIER, Suzanne. Transformação dos modos de socialização das crianças: uma abordagem sociológica. In: Revista Educação \& Sociedade. N. 91. Vol. 26. Mai/ago. 2005. p.391-404.

MONTANDON, Cléopâtre. Sociologia da Infância: balanços dos trabalhos de língua inglesa. In: Cadernos de Pesquisa, $\mathrm{n}^{\circ} 112$, p. 33-60. março/2001.

MÜLLER, Fernanda \& NUNES, Brasilmar F. Infância e cidade: um campo de estudo em desenvolvimento. In: Revista Educação \& Sociedade, v. 35, n. 128, p. 629-996, jul-set/2014.

PLAISANCE, Eric. Para uma sociologia da pequena infância. In: Revista Educação \& Sociedade, Campinas, vol. 25, n. 86, p.221-241, Abril. 2004.

PROUT, Alan. The future of childhood: towards the interdisciplinary study of children. Great Britain: RoutledgeFalmer. 2005.

SARMENTO, Manuel J; FERNANDES, Natália \& TOMÁS, Catarina. Políticas Públicas e Participação Infantil. In: Revista Educação, Sociedade \& Culturas, n. 25. 2007. p. 183-206.

SARMENTO, Manuel Jacinto. Gerações e Alteridade: interrogações a partir da sociologia da infância. In: Revista Educação \& Sociedade. N. 91. Vol. 26. Mai/ago. 2005. p. 361-378.

SIROTA, Régine. Emergência de uma Sociologia da Infância: evolução do objeto e do olhar. In: Cadernos de Pesquisa, $\mathrm{n}^{\mathrm{o}}$ 112, p. 07-31. março/2001.

\section{O LUGAR E O TEMPO DAS CULTURAS INFANTIS NAS PESQUISAS BRASILEIRAS}

Resumo: a presente reflexão teve como objetivo compreender o lugar e os tempos nos quais os estudos envolvendo as culturas infantis foram realizados nas pesquisas brasileiras por meio de uma pesquisa bibliográfica. Os resultados encontrados nos permitem afirmar que a maioria das pesquisas analisadas estudaram as culturas infantis no espaço da educação infantil e nos anos iniciais do ensino fundamental, ou seja, a discussão dessa temática tem sido estudada considerando como centralidade a territorialidade e o tempo escolar/institucionalizado. Palavras-Chave: culturas infantis - território - criança

\section{THE PLACE AND TIME OF CHILDREN'S CULTURES IN BRAZILIAN RESEARCH}

Abstract: The present study aimed to understand the place and times in which studies involving children ' $s$ cultures were carried out in Brazilian research through a bibliographical research. The results allow us to state that most of the studies analyzed studied children's cultures in the area of early childhood education and in the early years of elementary school, that is, the discussion of this theme has been studied considering as centrality territoriality and school/institutionalized time. Keywords: children's cultures - territory - child

\section{EL LUGAR Y EL TIEMPO DE LAS CULTURAS INFANTILES EN LAS INVESTIGAS BRASILEÑA}

Resumen: la presente reflexión tuvo como objetivo comprender el lugar y los tiempos en que los estudios involucrando las culturas infantiles se realizaron en las encuestas brasileñas a través de una investigación bibliográfica. Los resultados encontrados nos permiten afirmar que la mayoría de las investigaciones analizadas estudiaron las culturas infantiles en el espacio de la educación infantil y en los años iniciales de la enseñanza fundamental, o sea, la discusión de esta temática ha sido estudiada considerando como centralidad la territorialidad y el tiempo escolar/institucionalizado. Palabras clave: culturas infantiles - territorio - niño 